\title{
A New Approach to Nicotine: Symmetry Consideration for Synthesis Design
}

\author{
by Tse-Lok Ho* and Eugene V. Kuzakov
}

Department of Applied Chemistry, National Chiao Tung University, Hsinchu, Taiwan, Republic of China (e-mail: tlho@cc.nctu.edu.tw)

A synthesis of nicotyrine (9), and hence formally racemic nicotine, was carried out by elaboration of the $1: 1$ adduct 2 of cycloocta-1,5-diene and chlorosulfonyl isocyanate $\left(\mathrm{ClSO}_{2}-\mathrm{NCO}\right)$. Transformation of adduct 2 into carbamate 4 was followed by ozonolysis, tosylation, and $\mathrm{NaH}$ treatment, which led to pyrrolidinylpiperidinone 6. $\mathrm{LiAlH}_{4}$ Reduction, debenzylation, and aromatization yielded $\mathbf{2}$.

Nicotine (1) is widely occurring in the plant kingdom and a most well-known member of alkaloids [1]. It is the addictive constituent of tobacco and, therefore, its effects are directly related to the socioeconomic issue of tobacco smoking, although scientific evidence has exonerated the carcinogenic role for nicotine ${ }^{1}$ ). Historically significant is the fact that Pictet and Rotschy at the University of Geneva described the first synthesis of $( \pm)$-nicotine in 1904 via nornicotyrine, which arose from pyrolysis of 1(pyridin-3-yl)-1H-pyrrole [2]. This key step is now regarded as involving a [1,5]sigmatropic rearrangement that achieved the bonding reorganization ( $\mathrm{N}$-to-C shift of the pyridin-3-yl group followed by $\mathrm{C}$-to-N move of an $\mathrm{H}$-atom) [3]. Practically all the later syntheses started from pyridine derivatives in which a $\mathrm{C}$-substituent is located at $\mathrm{C}(3)$ [4] (an exception is a biomimetic route [5]; for a preparation of nicotyrine from 3iodopyridine, see $[5 b])$.

Our interest in a synthesis of nicotine stemmed from an analysis of bond connectivity in relation to hidden symmetry elements [6]. It was noted that an intermediate containing a 1,8-diaminooct-4-ene unit or some modifications thereof (see Fig. 1) would be viable because simultaneous addition of a single C-chain and one of the $\mathrm{N}$-atoms to the $\mathrm{C}=\mathrm{C}$ bond would provide all the skeletal atoms of nicotine. Regioselectivity in the addition is not an issue because of the inherent molecular symmetry that is exhibited by the oct-4-ene derivative (see Fig. 2).

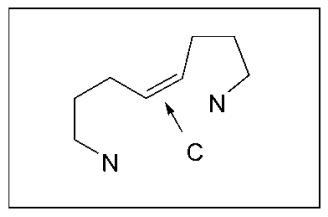

Fig. 1. Assembly mode of Nicotiana alkaloids

1) Nornicotine is a probable carcinogen due to its transformation into an $N$-nitrosamine derivative. Interestingly, it shows promise in alleviating Alzheimer's disease. 


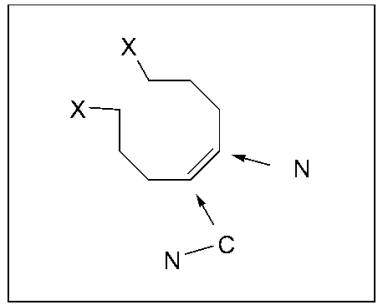

Fig. 2. Assembly mode evolved from Fig. 1

Further consideration of the scheme led to a refinement. As a result, we decided to develop a route starting with cycloocta-1,5-diene. Not only the starting material fulfills our symmetry consideration, but the 1 : 1-adduct $2\left(\mathrm{R}=\mathrm{SO}_{2} \mathrm{Cl}\right)$ of cycloocta-1,5-diene and chlorosulfonyl isocyanate $\left(\mathrm{ClSO}_{2}-\mathrm{NCO}\right)$ that we require is a known compound [7]. Accordingly, our work began by aminolysis of $2(\mathrm{R}=\mathrm{H})$ with benzylamine. The ring opening with benzylamine afforded $\beta$-aminoamide $\mathbf{3}$ that was subsequently protected by reaction with methyl carbonochloridate. Ozonolysis of carbamate 4 followed by a reductive workup with $\mathrm{NaBH}_{4}$ yielded diol 5. One of the $\mathrm{CH}_{2} \mathrm{OH}$ centers is separated from the $\mathrm{N}$-atoms by four and six bonds, while the other $\mathrm{CH}_{2} \mathrm{OH}$ center is related to both $\mathrm{N}$-atoms by five bonds. Activation of both $\mathrm{OH}$ groups of $\mathbf{5}$ to induce twofold intramolecular $N$-alkylations may lead to a fused diazabicyclo[5.4.0]undecane or hexahydronicotine derivative $\mathbf{6}$. We were quite confident that the second cyclization would proceed rapidly to give a pyrrolidine product hence that our expectation of a<smiles>CN1CCCC1c1cccnc1</smiles>

1<smiles></smiles>

5<smiles>[R]N1C(=O)[C@H]2CCC=CCC[C@H]21</smiles>

$2 \mathrm{R}=\mathrm{SO}_{2} \mathrm{Cl}$<smiles>COC(=O)N1CCC[C@H]1C1CCCN(Cc2ccccc2)C1=O</smiles>

6<smiles>Cn1cccc1-c1cccnc1</smiles>

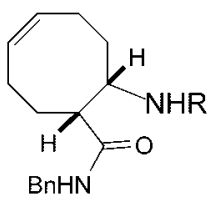

$3 \mathrm{R}=\mathrm{H}$

$4 \mathrm{R}=\mathrm{COOMe}$<smiles></smiles>

$7 \mathrm{R}=\mathrm{Bn}$

$8 \mathrm{R}=\mathrm{H}$ 
nicotine synthesis would be achievable. Therefore, tosylation of diol $\mathbf{5}$ was carried out. As partial cyclization of the ditosylate already occurred, we treated the crude product mixture with $\mathrm{NaH}$ to complete the formation of $\mathbf{6}$. While lactam $\mathbf{6}$ was obtained as a diastereoisomer mixture due to epimerization of the ditosylate prior to or during cyclization, it should be emphasized that the alternative mode of cyclization was not observed.

At this stage, we attempted to transform the piperidinone moiety of $\mathbf{6}$ into a pyridin-2 $(1 H)$-one. Due to unsatisfactory direct dehydrogenation or transformations involving $\alpha$-halogenation and dehydrohalogenation, we next reduced 6 with $\mathrm{LiAlH}_{4}$ to $N$-benzylhexahydronicotine (7) [8]. Hydrogenolysis of 7 furnished hexahydronicotine (8) [7] but its partial aromatization was technically tricky. Total dehydrogenation to afford nicotyrine (9) was accomplished by heating with Se powder. This represents a formal synthesis of nicotine as the selective reduction of the pyrrole ring is known [1][9].

In summary, we report a new route to the nicotine alkaloids based on symmetry consideration, proceeding via the same intermediate as described in the pioneering work of Pictet and Rotschy [2] on its centenary.

We thank the National Science Council of ROC for financial support.

\section{Experimental Part}

General. Column chromatography (CC): Merck silica-gel (63-200 mesh). TLC: Merck silica-gel 60 F254 plates. M.p.: uncorrected; Laboratory Devices. IR Spectra: Bio-Rad FTS 165; $\tilde{v}$ in $\mathrm{cm}^{-1} .{ }^{1} \mathrm{H}-$ and ${ }^{13} \mathrm{C}-\mathrm{NMR}$ Spectra: Varian Unity-300; $\mathrm{CDCl}_{3}$ as solvent unless otherwise indicated; $\delta$ in ppm, $J$ in Hz. EI-MS: Trio-2000 and Jeol $S X-102 A$; ionization potential $70 \mathrm{eV}$.

8-Amino-N-benzylcyclooct-4-ene-1-carboxamide (3). Benzylamine $(9.0 \mathrm{~g}, 84 \mathrm{mmol})$ was mixed with a soln. of lactam $2(10.6 \mathrm{~g}, 70 \mathrm{mmol})$ in dry toluene $(60 \mathrm{ml})$, and the mixture was refluxed under $\mathrm{N}_{2}$ for $36 \mathrm{~h}$. The cooled mixture was evaporated, and the residue was subjected to distillation at $<140^{\circ} / 1$ Torr to remove excess benzylamine. The remaining viscous oil $(15.5 \mathrm{~g})$ was directly used for derivatizing into the carbamate. For characterization, a portion of this oil was shaken with a sufficient amount of $6 \mathrm{~N} \mathrm{HCl}$, and the aq. phase was washed twice with $\mathrm{CH}_{2} \mathrm{Cl}_{2}$, basified with $10 \% \mathrm{NaOH}$ soln. to $\mathrm{pH} 10$ and extracted with $\mathrm{CH}_{2} \mathrm{Cl}_{2}$. The combined org. extract was dried $\left(\mathrm{Na}_{2} \mathrm{SO}_{4}\right)$ and evaporated: 3. Yellow oil. IR: $3416(\mathrm{~N}-\mathrm{H}), 2932(\mathrm{C}-\mathrm{H}), 1644(\mathrm{C}=\mathrm{O})$. ${ }^{1} \mathrm{H}-\mathrm{NMR}: 1.65-2.27(m, 8 \mathrm{H}) ; 2.49(m, 1 \mathrm{H}) ; 3.29(m, 1 \mathrm{H}) ; 4.33(d, J=5.4,2 \mathrm{H}) ; 5.53(d m, J=10.5,1 \mathrm{H}) ; 5.66$ $(d m, J=10.5,1 \mathrm{H}) ; 7.17-7.27(m, 5 \mathrm{H}) ; 8.01$ (br., NH) $.{ }^{13} \mathrm{C}-\mathrm{NMR}: 23.27(t) ; 24.65(t) ; 28.14(t) ; 36.14(t) ; 42.68$ $(t) ; 47.23(d) ; 51.57(d) ; 126.88(d) ; 127.23(2 \mathrm{C}, d) ; 128.30(2 \mathrm{C}, d) ; 128.86(d) ; 130.98(d) ; 138.74(s) ; 176.47(s)$. EI-MS: $258\left(12, M^{+\bullet}\right), 162(13), 162(17), 124(19), 123(25), 107$ (12), 106 (38), 97 (18), 96 (18), 91 (100). HRMS: $258.1727\left(\mathrm{C}_{16} \mathrm{H}_{22} \mathrm{~N}_{2} \mathrm{O}^{+\cdot} ;\right.$ calc. 258.1733).

\{8-[(Benzylamino)carbonyl]cyclooct-4-en-1-yl\}carbamic Acid Methyl Ester (4). A stirred soln. of crude 3 $(15.0 \mathrm{~g})$, pyridine $(5.1 \mathrm{~g})$, and $\mathrm{N}, \mathrm{N}$-dimethylpyridin-4-amine (DMAP; $0.05 \mathrm{~g})$ in dry $\mathrm{CH}_{2} \mathrm{Cl}_{2}(50 \mathrm{ml})$ was cooled to $0^{\circ}$ and treated with a soln. of methyl carbonochloridate $\left(6.04 \mathrm{~g}\right.$ in $15 \mathrm{ml}$ of dry $\left.\mathrm{CH}_{2} \mathrm{Cl}_{2}\right)$ via dropwise addition during $20 \mathrm{~min}$. Stirring was continued for $2 \mathrm{~h}$ at $0^{\circ}$ and $3 \mathrm{~h}$ at r. t. Then the mixture was poured into cold $\mathrm{H}_{2} \mathrm{O}$ $(100 \mathrm{ml})$. The aq. phase was washed with $\mathrm{CH}_{2} \mathrm{Cl}_{2}(20 \mathrm{ml})$, the combined org. soln. washed twice with cold $\mathrm{H}_{2} \mathrm{O}$, dried $\left(\mathrm{Na}_{2} \mathrm{SO}_{4}\right)$, and evaporated, and the crude product chromatographed $\left(\mathrm{SiO}_{2}, \mathrm{AcOEt} / \mathrm{hexane} 4: 6\right): 4(10.6 \mathrm{~g}$, $48 \%$ over 2 steps $)$. IR: $3315(\mathrm{~N}-\mathrm{H}), 2945(\mathrm{C}-\mathrm{H}), 1698,1657(\mathrm{C}=\mathrm{O}) .{ }^{1} \mathrm{H}-\mathrm{NMR}: 1.66-2.34(m, 8 \mathrm{H}) ; 2.68(m$, $1 \mathrm{H}) ; 3.52(s, 3 \mathrm{H}) ; 4.16(m, 1 \mathrm{H}) ; 4.31(d, J=5.4,2 \mathrm{H}) ; 5.45(d, J=8.1) ; 5.58(m, 2 \mathrm{H}) ; 5.65(m, 2 \mathrm{H}) ; 7.15-7.25$ $(m, 5 \mathrm{H}) .{ }^{13} \mathrm{C}-\mathrm{NMR}: 22.69(t) ; 25.59(t) ; 27.83(t) ; 33.15(t) ; 43.01(t) ; 48.50(d) ; 50.57(d) ; 51.88(q) ; 126.90(d)$; $127.21(2 \mathrm{C}, d) ; 128.24(2 \mathrm{C}, d) ; 129.83(d) ; 130.06(d) ; 138.33(s) ; 156.54(s) ; 174.45(s)$. EI-MS: $316\left(16, M^{+*}\right), 288$ (11), 162 (46), 149 (14), 128 (16), 108 (15), 107 (18), 106 (100), 91 (90), 79 (17). HR-MS: 316.1791 $\left(\mathrm{C}_{18} \mathrm{H}_{24} \mathrm{~N}_{2} \mathrm{O}_{3}^{+*}\right.$; calc. 316.1787).

\{2-[(Benzylamino)carbonyl]-5-hydroxy-1-(3-hydroxypropyl)pentyl $\}$ carbamic Acid Methyl Ester (5). A stream of $\mathrm{O}_{3} / \mathrm{O}_{2}$ was bubbled through a soln. of $\mathbf{3}(7.5 \mathrm{~g}, 24 \mathrm{mmol})$ in $\mathrm{MeOH} / \mathrm{CH}_{2} \mathrm{Cl}_{2} 1: 1(40 \mathrm{ml})$ at $-80^{\circ}$ until a 
blue color appeared and a crystalline precipitate formed (after $c a .1 .25 \mathrm{~h}$ ). The soln. was purged with $\mathrm{N}_{2}$ while maintaining the low temp. until the blue color disappeared. Dimethyl sulfide $(11 \mathrm{ml})$ and then $\mathrm{NaBH}_{4}(4.5 \mathrm{~g}$, $0.12 \mathrm{~mol}$ ) were added in portions under $\mathrm{N}_{2}$. After the addition, the cooling bath was removed, and the mixture was stirred for $1 \mathrm{~h}$. Solvents were evaporated, and the residue was washed with $\mathrm{H}_{2} \mathrm{O}$ and $\mathrm{CH}_{2} \mathrm{Cl}_{2}$, collected, and dried to constant weight. Recrystallization of the solid gave 5 (6.82 g, 82\%). M.p. 158-161 ${ }^{\circ}$ ( $\mathrm{MeOH} / \mathrm{AcOEt}$ 1:2). IR: 3305, $3280(\mathrm{~N}-\mathrm{H}, \mathrm{O}-\mathrm{H}), 2951(\mathrm{C}-\mathrm{H}), 1695,1630(\mathrm{C}=\mathrm{O}) .{ }^{1} \mathrm{H}-\mathrm{NMR}\left(\left(\mathrm{D}_{5}\right)\right.$ pyridine $): 1.87-2.40(m$, $8 \mathrm{H}) ; 3.02(m, 1 \mathrm{H}) ; 3.67(s, 3 \mathrm{H}) ; 3.88(m, 4 \mathrm{H}) ; 4.59(m, 1 \mathrm{H}) ; 4.71(d, J=5.4,2 \mathrm{H}) ; 5.21(\mathrm{~s}, \mathrm{OH}) ; 7.18-7.33(m$, $3 \mathrm{H}) ; 7.52(d, J=7.5,2 \mathrm{H}) ; 8.22(d, J=9.0,1 \mathrm{H}) ; 9.53(t, J=6.0,1 \mathrm{H}) .{ }^{13} \mathrm{C}-\mathrm{NMR}: 27.02(t) ; 30.06(t) ; 30.26(t)$; $31.62(t) ; 43.12(t) ; 51.43(q) ; 52.66(d) ; 54.00(d) ; 61.73(t) ; 61.80(t) ; 126.94(d) ; 127.89(2 \mathrm{C}, d) ; 128.50(2 \mathrm{C}, d)$; $140.05(s) ; 157.83(s) ; 174.25(s)$. EI-MS : $352\left(3, M^{+\bullet}\right), 207(44), 162(112), 132(110), 106(82), 105(88), 91$ (99), 90 (77), 76 (54). HR-MS: $352.1995\left(\mathrm{C}_{18} \mathrm{H}_{28} \mathrm{~N}_{2} \mathrm{O}_{5}^{+} \cdot\right.$; calc. 352.1997).

2-(1-Benzyl-2-oxopiperidin-3-yl)pyrrolidine-1-carboxylic Acid Methyl Ester (6). To a soln. of 5 (3.05 g, $8.7 \mathrm{mmol})$ and $\mathrm{Et}_{3} \mathrm{~N}(1.93 \mathrm{~g}, 19 \mathrm{mmol})$ in anh. THF $(80 \mathrm{ml})$, a soln. of TsCl $(4.12 \mathrm{~g}, 22 \mathrm{mmol})$ in THF (20 ml) was added dropwise within $15 \mathrm{~min}$ at $0^{\circ}$. The mixture was warmed to r. t. while stirring for $3 \mathrm{~h}$, and then brought to reflux for $6 \mathrm{~h}$. After cooling, the solvent was evaporated, and the residue was dissolved in $\mathrm{CH}_{2} \mathrm{Cl}_{2}(70 \mathrm{ml})$. The soln. was washed twice with sat. $\mathrm{NaHCO}_{3}$ soln. and brine, dried $\left(\mathrm{Na}_{2} \mathrm{SO}_{4}\right)$ and evaporated: mixture of ditosylate and partially cyclized product (3.82 g) (by NMR). This residue was dissolved in anh. THF (70 ml), the soln. cooled to $0^{\circ}$, and $\mathrm{NaH}(1.73 \mathrm{~g}, 60 \%$ dispersion in mineral oil, $43.5 \mathrm{mmol})$ added under $\mathrm{N}_{2}$. After $20 \mathrm{~min}$, the cooling bath was removed and the mixture refluxed for $7 \mathrm{~h}$. After cooling, the mixture was partitioned between $\mathrm{CH}_{2} \mathrm{Cl}_{2}(70 \mathrm{ml})$ and $\mathrm{H}_{2} \mathrm{O}(100 \mathrm{ml})$, the aq. phase extracted with more $\mathrm{CH}_{2} \mathrm{Cl}_{2}(2 \times 30 \mathrm{ml})$, the combined org. phase washed with brine, dried $\left(\mathrm{Na}_{2} \mathrm{SO}_{4}\right)$ and evaporated, and the the residue subjected to CC (silica gel, 30\% AcOEt/hexane): 6 (1.46 g, 53\% over 2 steps $), 1: 1$ mixture of the erythro- and threo-isomers. IR: 2948, 2871 $(\mathrm{C}-\mathrm{H}), 1694,1627(\mathrm{C}=\mathrm{O}) .{ }^{1} \mathrm{H}-\mathrm{NMR}: 1.50-1.78(m, 8 \mathrm{H}) ; 2.06(m, 1 \mathrm{H}) ; 3.09(m, 2 \mathrm{H}) ; 3.20(m, 1 \mathrm{H}) ; 3.31(m$, $1 \mathrm{H}) ; 3.59(s, 3 \mathrm{H}) ; 4.49$ (br., $2 \mathrm{H}) ; 4.57(m, 1 \mathrm{H}) ; 7.13-7.24(m, 5 \mathrm{H}) .{ }^{13} \mathrm{C}-\mathrm{NMR}: 21.76(t) ; 21.88(t) ; 23.55,23.97$ ( $2 t, 2$ isomers); 27.41, 28.07 ( $2 t, 2$ isomers); $42.98,44.36$ ( $2 d, 2$ isomers); $46.97(t) ; 49.75(t) ; 51.80,52.07(2 q, 2$ isomers); $57.46,58.06(2 d, 2$ isomers $) ; 126.94(d) ; 127.68(2 \mathrm{C}, d) ; 128.24(2 \mathrm{C}, d) ; 137.17(s) ; 155.50(s) ; 170.36$, $170.65\left(2 s, 2\right.$ isomers). EI-MS: $316\left(47, M^{+} \cdot\right), 257(68), 189(100), 160(13), 159(16), 128(76), 128(75), 91(90)$, 82 (15). HR-MS: $316.1787\left(\mathrm{C}_{18} \mathrm{H}_{24} \mathrm{~N}_{2} \mathrm{O}_{3}^{+*} ;\right.$ calc. 316.1787$)$.

$\mathrm{N}$-Benzylhexahydronicotine (=1-Benzyl-3-(1-methylpyrrolidin-2-yl)piperidine; 7). A soln. of 6 (0.3 g, $0.95 \mathrm{mmol})$ in anh. THF $(3 \mathrm{ml})$ was added dropwise to a stirred suspension of $\mathrm{LiAlH}_{4}(0.18 \mathrm{~g}, 4.72 \mathrm{mmol})$ in THF ( $7 \mathrm{ml}$ ) under $\mathrm{N}_{2}$. The mixture was refluxed for $12 \mathrm{~h}$, cooled, and quenched with wet THF, then with $\mathrm{H}_{2} \mathrm{O}$. Addition of $1 \mathrm{~N} \mathrm{NaOH}(5 \mathrm{ml})$ led to a precipitate that was filtered. The filter cake was washed with THF and $\mathrm{MeOH}$ (10 $\mathrm{ml}$ each), and the org. solns were combined and evaporated. The residue was partitioned between $\mathrm{H}_{2} \mathrm{O}(15 \mathrm{ml})$ and $\mathrm{CH}_{2} \mathrm{Cl}_{2}(3 \times 10 \mathrm{ml})$, and usual workup led to $7(0.24 \mathrm{~g})$.

Hexahydronicotine ( =3-(1-Methylpyrrolidin-2-yl)piperidine; 8). Compound 7 (0.24 g) was debenzylated under hydrogenolysis conditions. The crude product was percolated through a $\mathrm{SiO}_{2}$ column with $40 \% \mathrm{AcOEt} /$ hexane: 8 (0.14 g).

Nicotyrine (=3-(1-Methyl-1H-pyrrol-2-yl)pyridine; 9). A soln. of $7(0.11 \mathrm{~g}, 0.33 \mathrm{mmol})$ in $\mathrm{CH}_{2} \mathrm{Cl}_{2}(2 \mathrm{ml})$ was added dropwise to Se powder $(0.47 \mathrm{~g}, 5.9 \mathrm{mmol})$. The solvent was carefully evaporated and the mixture was heated at $250-260^{\circ}$ for $30 \mathrm{~h}$ under $\mathrm{N}_{2}$. The mixture was cooled and the residue scratched off from the flask, smashed to a fine powder in a mortar, and extracted with boiling $\mathrm{CH}_{2} \mathrm{Cl}_{2}(20 \mathrm{ml})$. Filtration and evaporation left a black mass which was chromatographed $\left(\mathrm{SiO}_{2}, 15-30 \%\right.$ AcOEt/hexane: $9(0.02 \mathrm{~g}, 18 \%) .{ }^{1} \mathrm{H}-\mathrm{NMR}: 3.65(s$, $3 \mathrm{H}) ; 6.21,6.27,6.75$ (br., $1 \mathrm{H}$ each $) ; 7.30(d m, J=7.8,1 \mathrm{H}) ; 7.68(d m, J=7.8,1 \mathrm{H}) ; 8.50(d, J=3.9,1 \mathrm{H}) ; 8.66$ (br., $1 \mathrm{H}) .{ }^{13} \mathrm{C}$-NMR: $35.02(q) ; 108.16(d) ; 109.72(d) ; 123.18(d) ; 124.68(d) ; 129.21(s) ; 130.72(s) ; 135.44(d)$; $147.58(d) ; 149.12(d)$. EI-MS: $158\left(100, M^{+} \cdot\right), 157(39), 130(11)$.

\section{REFERENCES}

[1] L. Marion, in 'The Alkaloids', Eds. R. H. F. Manske and H. L. Holmes, Academic Press, New York, 1950, Vol. 1, p. 228; L. Marion, in 'The Alkaloids', Ed. R. H. F. Manske, Academic Press, New York, 1960, Vol. 6, p. 128; W. A. Ayer, T. E. Habgood, in 'The Alkaloids', Ed. R. H. F. Manske, Academic Press, New York, 1968, Vol. 11, p. 477; G. M. Strunz, J. A. Findlay, in 'The Alkaloids', Ed. A. Brossi, Academic Press, Orlando, 1985, Vol. 26, p. 121.

[2] A. Pictet, A. Rotschy, Ber. Dtsch. Chem. Ges. 1904, 37, 1225.

[3] R. B. Woodward, R. Hoffmann, J. Am. Chem. Soc. 1965, 87, 395. 
[4] M. Nakane, C. R. Hutchinson, J. Org. Chem. 1978, 43, 3922 and ref. cit. therein; G. F. Alberici, J. Andrieux, G. Adam, M. M. Plat, Tetrahedron Lett. 1983, 24, 1937.

[5] a) E. Leete, J. Chem. Soc., Chem. Commun. 1972, 1091; b) H.-S. Ryang, H. Sakurai, J. Chem. Soc., Chem. Commun. 1972, 594.

[6] T.-L. Ho, 'Symmetry. A Basis for Synthesis Design', John Wiley \& Sons, New York, 1995.

[7] P. J. Parsons, N. P. Camp, J. M. Underwood, D. M. Harvey, Tetrahedron 1996, 52, 11637.

[8] M. Shibagaki, H. Matsushita, H. Kaneko, Heterocycles 1985, 23, 2351.

[9] E. Späth, F. Kuffner, Ber. Dtsch. Chem. Ges. 1935, 68, 494. 